\title{
Template-free synthesis of hierarchical porous $\mathrm{SnO}_{2}$
}

\author{
Guisheng Li $\cdot$ Michael K. H. Leung
}

Received: 8 September 2009/ Accepted: 27 November 2009/Published online: 15 December 2009

(C) Springer Science+Business Media, LLC 2009

\begin{abstract}
Hierarchical porous tin dioxide has been successfully prepared through a fast one-pot template-free synthesis route. The boiling of the mixture of alcohol and glycerol can be utilized to generate nanopores in the $\mathrm{SnO}_{2}$ monolith. Polycrystalline hierarchical $\mathrm{SnO}_{2}$ with well proportioned composition has also been obtained in the pore walls of tin dioxide.
\end{abstract}

Keywords Hierarchical $\cdot$ Porous $\cdot \mathrm{SnO}_{2} \cdot$ One-pot . Template-free

\section{Introduction}

Tin dioxide $\left(\mathrm{SnO}_{2}\right)$ is becoming an important inorganic material owing to its myriad technologically important applications. As an n-type wide-band semiconductor $(\mathrm{Eg}=3.6 \mathrm{eV}, 300 \mathrm{~K})$, it is widely used in many areas such as gas sensor [1, 2], electrode material [3, 4], solar cells [5, 6], and catalysts [7]. For these key functional applications, it has been prepared through a wide variety of synthetic approaches such as solvothermal method, spray pyrolysis, sputtering, solution-phase growth, vapor-liquid-solid (VLS) growth, and molten salt synthesis, among others [8-13]. Up to now, different novel morphologies of $\mathrm{SnO}_{2}$, such as nanoparticles, nanorods, nanotubes, nanodiskettes, nanoboxes, hollow

\footnotetext{
G. Li (凹)

Department of Chemistry, Shanghai Normal University, 200234 Shanghai, People's Republic of China

e-mail: lgscuhk@yahoo.com.cn

G. Li · M. K. H. Leung $(\bowtie)$

Department of Mechanical Engineering, The University of Hong Kong, Pokfulam Road, Hong Kong, People's Republic of China e-mail: mkhleung@hku.hk
}

spheres, and mesoporous structures [14-21], have been designed. As known, the hierarchical porous material has been studied extensively for its wide applications such as HPLC separation, bone-tissue implants, catalysis, electrode materials for fuel cell application, heterogeneous colorimetric sensors, biomaterials engineering and controlled drug delivery devices, photovoltaic cells and energy conversion applications [22-29]. To the best of our knowledge, the production of hierarchical porous $\mathrm{SnO}_{2}$ has never been reported before. Herein, we present a simple one-pot template-free route to synthesize hierarchical porous $\mathrm{SnO}_{2}$ nanocrystals. The synthesis procedure is performed in an ethanol-glycerol mixed solvent using tin tetrachloride hydrate $\left(\mathrm{SnCl}_{4} \cdot 2 \mathrm{H}_{2} \mathrm{O}\right)$ as the precursor. Such method is convenient and environmentally friendly because it avoids the complicated procedure of removing the templates. It could also allow scientific researchers to fabricate other metal oxides nanocrystals, such as $\mathrm{TiO}_{2}, \mathrm{ZnO}$, and so on.

\section{Experimental}

\subsection{Preparation}

In a typical synthesis procedure, $1.0 \mathrm{~g}$ of $\mathrm{SnCl}_{4} \cdot 2 \mathrm{H}_{2} \mathrm{O}$ (Aldrich) was dissolved in a mixture solution, containing $15 \mathrm{~mL}$ of glycerol (Aldrich) and $10 \mathrm{~mL}$ of ethanol, with vigorous stirring for $12 \mathrm{~h}$ to form a transparent solution. The as-prepared solution was transferred to a Petri dish with a diameter of $12.0 \mathrm{~cm}$ and calcined at $350{ }^{\circ} \mathrm{C}$ at $2.0^{\circ} \mathrm{C} / \mathrm{min}$ for $8 \mathrm{~h}$ in a muffle furnace. Then, the calcination temperature was further increased to $400{ }^{\circ} \mathrm{C}$ at $5.0^{\circ} \mathrm{C} / \mathrm{min}$ for $5 \mathrm{~h}$. This procedure aimed to crystallize $\mathrm{SnO}_{2}$ and to remove the remaining carbon element in the as-prepared samples. 


\subsection{Characterization}

Wide-angle X-ray diffraction measurements were carried out in a parallel mode $\left(\omega=0.5^{\circ}, 2 \theta\right.$ varied from $20^{\circ}$ to $\left.80^{\circ}\right)$ using a Bruker D8 Advance X-ray diffractometer $(\mathrm{Cu}$ $\mathrm{K} \alpha$ radiation, $\lambda=1.5406 \AA$ ). The size of the as-prepared $\mathrm{SnO}_{2}$ crystallites was estimated by using the Sherrer formula: $D=0.89 \lambda / \beta \cos \theta$, where $D$ is the crystal size, $\lambda$ is the wavelength of X-ray radiation $(0.15406$ for $\mathrm{Cu} \mathrm{K} \alpha$ radiation), $\beta$ is the full width at half maximum of the (110) peak of $\mathrm{SnO}_{2}$. The $\mathrm{N}_{2}$-sorption isotherms were recorded at $77 \mathrm{~K}$ in a Micromeritics ASAP 2010 instrument. All the samples were degassed at $150{ }^{\circ} \mathrm{C}$ and $10^{-6}$ torr for $24 \mathrm{~h}$ prior to the measurement. The Brunauer-Emmett-Teller approach was used to determine the surface area. Highresolution transmission electron microscopy (HRTEM) was recorded in JEOL-2010F at $200 \mathrm{kV}$. The electron microscopy samples were recorded prepared by grinding and dispersing the powder in acetone with ultrasonication for $20 \mathrm{~s}$. Carbon-coated copper grids were used as sample holders. The morphology of the samples was examined by a LEO 1450 VP scanning microscope coupled with an EDX spectrometer (Oxford Instruments). X-ray photoelectron spectroscopy (XPS) measurement was done with a PHI Quantum 2000 XPS system with a monochromatic $\mathrm{Al}-\mathrm{K} \alpha$ source and a charge neutralizer. All the binding energies were referenced to the $\mathrm{C}_{1 \mathrm{~s}}$ peak at $284.8 \mathrm{eV}$ of the surface adventitious carbon.

\section{Results and discussion}

Shown in Fig. 1 is X-ray diffraction pattern of the as-prepared sample of hierarchical porous $\mathrm{SnO}_{2}$. All diffraction peaks in the pattern can be indexed to a typical $\mathrm{SnO}_{2}$ tetragonal phase (JCPDS 41-1445). Characteristic peaks of any other impurities cannot be observed. Such structured nanocrystal of $\mathrm{SnO}_{2}$ owns a $\mathrm{P} 42 / \mathrm{mnm}$ space group with $Z=2$. The lattice parameter is calculated to be $a=b=4.736 \AA$, $c=3.184 \AA$, and $V=71.38 \AA^{3}$ which is consistent with the reported value (JCPDS-41-1445). In the tetragonal $\mathrm{SnO}_{2}$, the $\mathrm{Sn}$ atoms are octahedrally coordinated by $\mathrm{O}$ atoms. The size of the as-prepared $\mathrm{SnO}_{2}$ crystallites was estimated about $10.1 \mathrm{~nm}$ by using the Sherrer formula.

Figure 2 shows the energy dispersion X-ray (EDX) spectrum to confirm the composition of the as-prepared hierarchical porous $\mathrm{SnO}_{2}$. As shown, the chemical component of the as prepared sample is mainly composed of tin and oxygen. No obvious remaining carbon element can be detected in the as-prepared $\mathrm{SnO}_{2}$ nanocrystals. It illustrates that our proposed method is very efficient to synthesize high purity tetragonal $\mathrm{SnO}_{2}$. From the EDX patterns, the

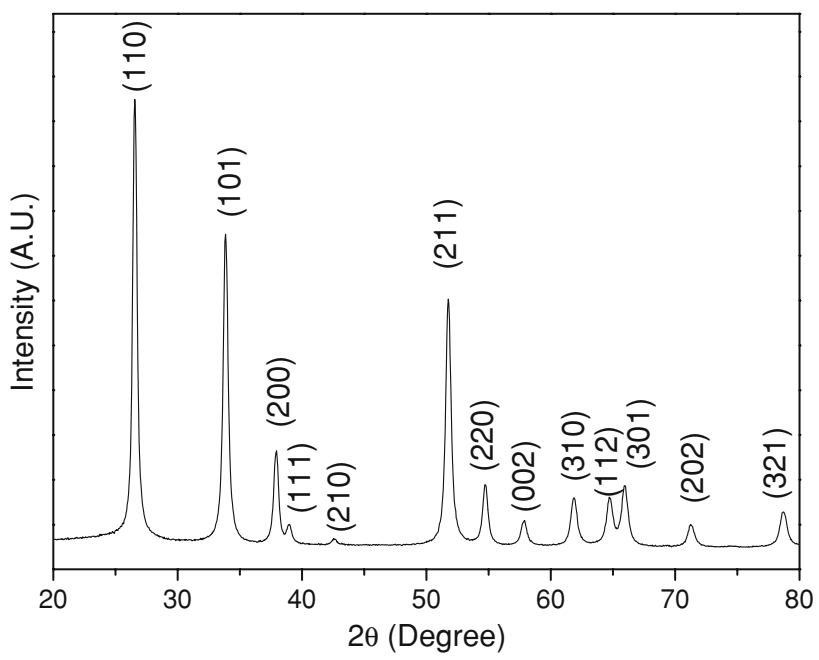

Fig. 1 XRD pattern of the as-prepared hierarchical porous $\mathrm{SnO}_{2}(\mathbf{a})$ and the crystal structure of tetragonal $\mathrm{SnO}_{2}$

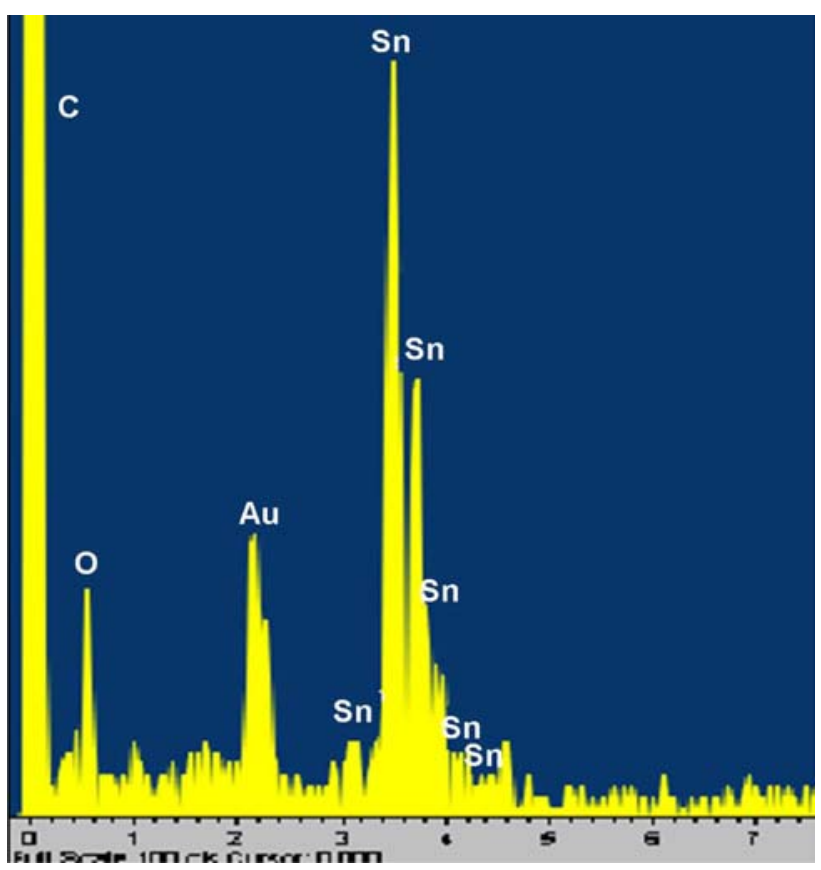

Fig. 2 EDX spectrum of the hierarchical porous $\mathrm{SnO}_{2}$

$\mathrm{Sn} / \mathrm{O}$ atomic ratio is computationally about $1: 2$, which is similar to atomic ratio of $\mathrm{Sn} / \mathrm{O}, 32.6: 67.4$, calculated based on the XPS results. XPS was further carried out to investigate the surface compositions and chemical states of the as-prepared materials. Figure $3 \mathrm{a}, \mathrm{b}$ exhibits the high-resolution XPS spectra corresponding to $\mathrm{Sn} 3 \mathrm{~d}$ and $\mathrm{O}$ 1s for the nanocrystalline porous $\mathrm{SnO}_{2}$. It appeared as a spin-orbit doublet at $\sim 486.4 \mathrm{eV}(3 \mathrm{~d} 5 / 2)$ and $\sim 495.0 \mathrm{eV}(3 \mathrm{~d} 3 / 2)$, which was in agreement with the reported value in the literature [30]. In the case of the $\mathrm{O} 1 \mathrm{~s}$ peaks, a shoulder at $\sim 531.5 \mathrm{eV}$ is observed with the main peak at $\sim 530.3 \mathrm{eV}$. 

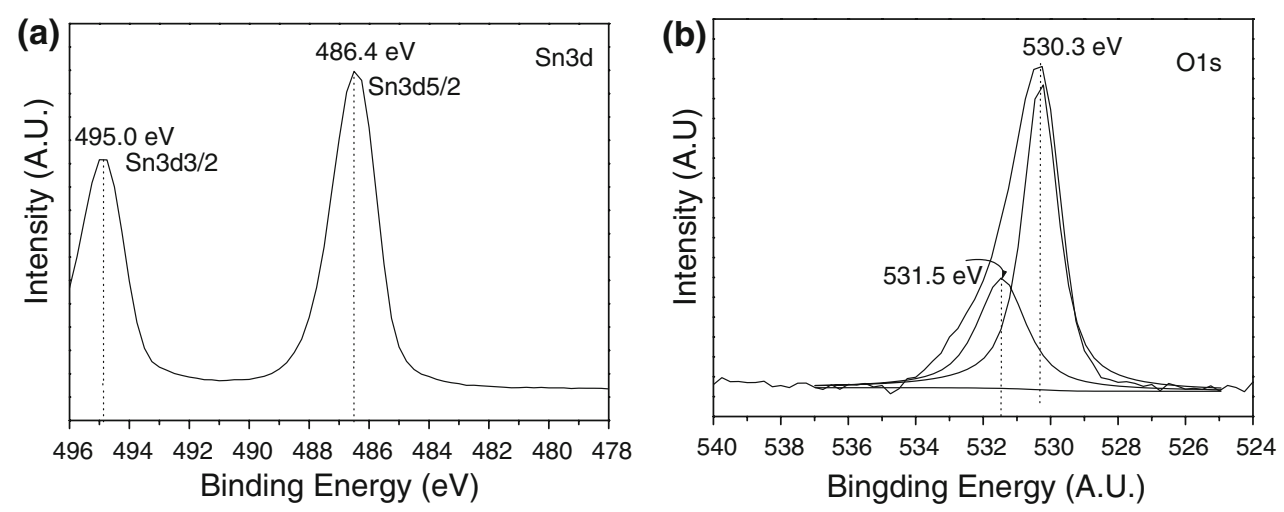

Fig. 3 (a, b) XPS profiles of the hierarchical porous $\mathrm{SnO}_{2}$

The main peak is assigned to the lattice oxygen, and the shoulder is due to the oxygen of the Sn-OH bonds [31, 32].

The textural properties of the as-prepared sample are confirmed by $\mathrm{N}_{2}$ sorption analyses. The specific surface area of the hierarchical $\mathrm{SnO}_{2}$ sample is about $60.0 \mathrm{~m}^{2} \mathrm{~g}^{-1}$ by using the Brunauer-Emmett-Teller (BET) method. Figure 4 shows the pore size distribution curve calculated from the desorption branch of a nitrogen isotherm by the BJH method using the Halsey equation. Two types of pores can be defined in the as-prepared sample, including small mesopores $(4.7 \mathrm{~nm})$ and large mesopores with a maximum pore diameter of ca. $31 \mathrm{~nm}$. The inset shows the corresponding nitrogen isotherm of the hierarchical $\mathrm{SnO}_{2}$. There are two capillary condensation steps on the $\mathrm{N}_{2}$ adsorptiondesorption isotherm. These results suggest that the hierarchical $\mathrm{SnO}_{2}$ is composed of independently connected mesopores. The first hysteresis loop, $0.35<P / P_{0}<0.86$, of the sample is attributed to the filling of the framework confined smaller mesopores formed between intraagglomerated primary particles [33]. The second hysteresis loop is at $0.86<P / P_{0}<1$, corresponding to the filling of

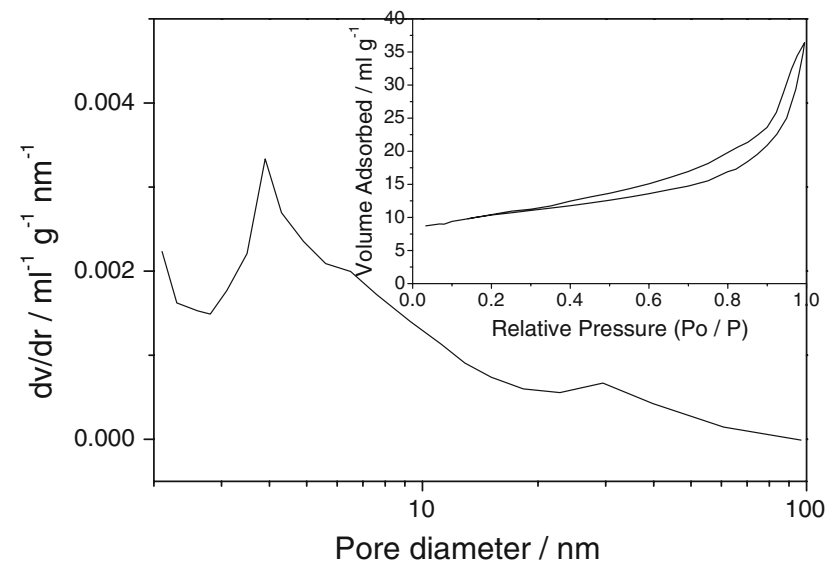

Fig. 4 Pore size distribution curve and (inset) corresponding isotherm of hierarchical porous $\mathrm{SnO}_{2}$ larger textural mesopores produced by inter-aggregated secondary particles.

Shown in Fig. 5 are typical SEM images of the hierarchical porous tin oxide. From Fig. 5a, one can see that the hierarchical $\mathrm{SnO}_{2}$ is composed of macroscopic network structures with lots of macropores ranging from ca. 30 to $300 \mu \mathrm{m}$ (size). Something interesting can be further found, from Fig. $5 \mathrm{~b}$, c, that the wall of these macropores is composed of numerous small $\mathrm{SnO}_{2}$ sheets of $1 \mu \mathrm{m}$ (thickness). All of these $\mathrm{SnO}_{2}$ sheets are overlapped each other to form a laminar structure with relatively homogeneous macropores of ca. 1-2 $\mu \mathrm{m}$ (size). Figure $5 \mathrm{~d}$ further shows an image of a single $\mathrm{SnO}_{2}$ sheet and it is composed of numerous small interconnected tin dioxide crystallites. It is worthy to note that these small crystallites aggregate to form a nanoporous structure in the $\mathrm{SnO}_{2}$ networks.

Figure 6 shows the HRTEM images of the as-prepared samples, no long-range order mesoporous structure can be found, though the mesoporous structures can been seen clearly. This is possibly related to the crystallization of the channel walls, which destroys the long-range order of mesoporous structure [34]. Therefore, the mesoporosity could mainly result from the interparticle porosity. HRTEM image of the as-prepared sample is shown in Fig. $6 \mathrm{~b}$, which gives the polycrystalline information of the hierarchical $\mathrm{SnO}_{2}$. Such small grains with a diameter of about $10 \mathrm{~nm}$ are distributed homogenously in the pore wall of $\mathrm{SnO}_{2}$ to form the interparticle pores. Such result is similar with that calculated from XRD spectra. Meanwhile, all of these grains are of well crystallized rutile $\mathrm{SnO}_{2}$ phase. Legible crystal lattice can be well defined in Fig. 6b. The observed interplanar spacing as marked is about 0.33 and $0.26 \mathrm{~nm}$, corresponding to the (110) plane and (101) plane of the rutile $\mathrm{SnO}_{2}$, respectively.

The possible shape mechanism for the as-prepared hierarchical porous $\mathrm{SnO}_{2}$ nanocrystals is demonstrated in Fig. 7. Two steps may play an important role in the synthesis procedure. The first one is the formation of a clear 


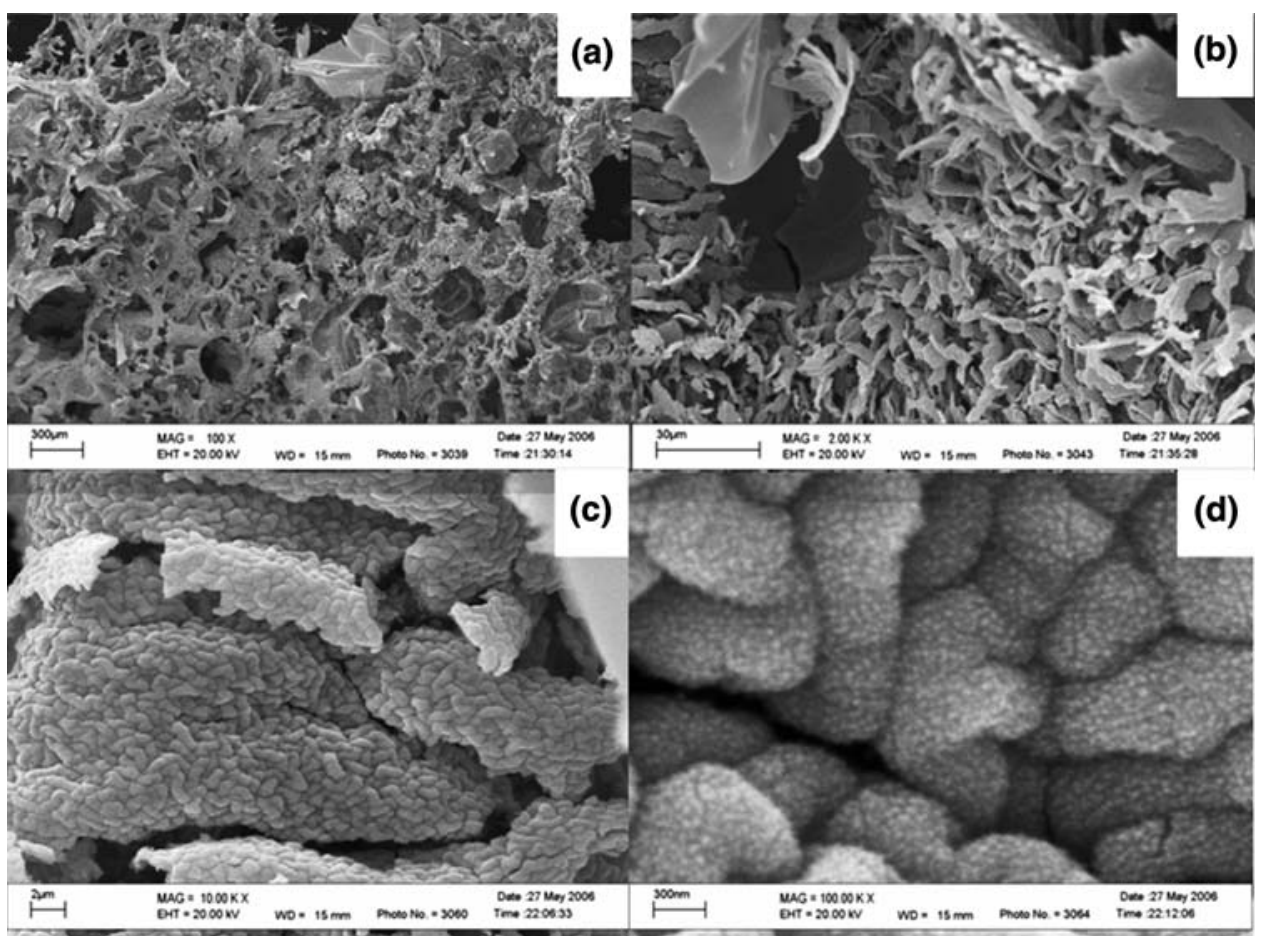

Fig. 5 SEM images $(\mathbf{a}, \mathbf{b})$ of the hierarchical porous $\mathrm{SnO}_{2}$ with different magnifications, $(\mathbf{c}, \mathbf{d})$ high resolution SEM images of both a and b
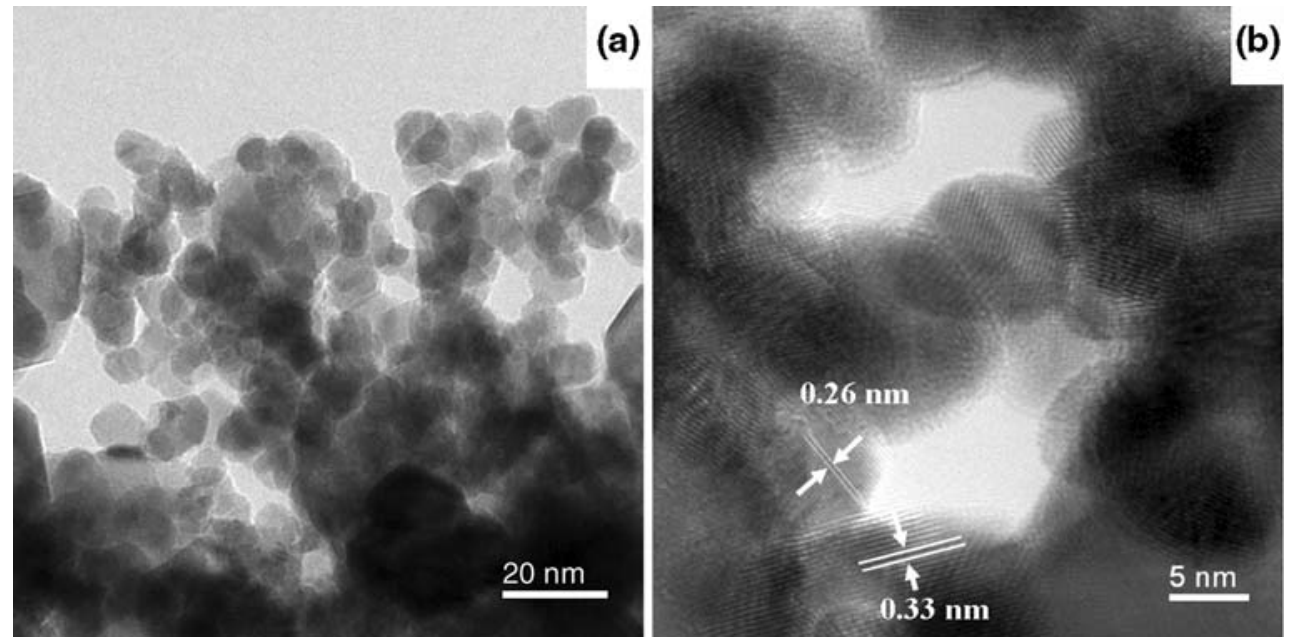

Fig. 6 TEM images of the hierarchical porous $\mathrm{SnO}_{2}$

mixture solution, containing ethanol, glycerol and tin tetrachloride hydrate, and the second one is boiling the alcohol to generate nanopores in the $\mathrm{SnO}_{2}$ gel through calcination. In the present work, we also noted that the hierarchical porous structure cannot be obtained in the absence of the clear mixture solution. Serious aggregation took place to the $\mathrm{SnO}_{2}$ grains. These phenomena show that a well-homogenous $\mathrm{SnCl}_{4}$ alcohol solution is the key determinant of the fabrication of hierarchical porous $\mathrm{SnO}_{2}$ nanocrystals. It could allow the alcohol bubbles to generate interparticle nanopores in the $\mathrm{SnO}_{2}$ monolith.

\section{Conclusions}

In summary, hierarchical porous stannic oxide $\left(\mathrm{SnO}_{2}\right)$ are successfully prepared through one-pot template-free synthesis route. In the synthesis, the boiling of the alcohol is 


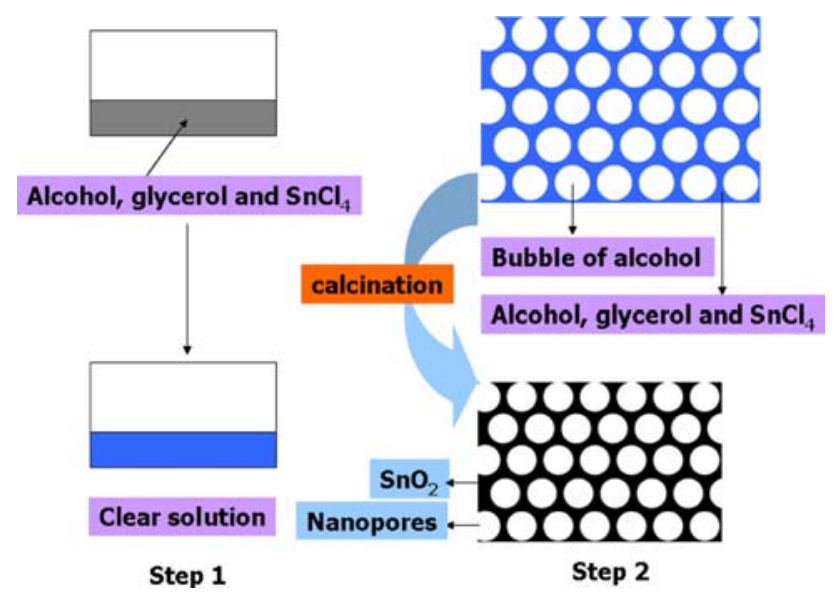

Fig. 7 Shape mechanism of the hierarchical porous $\mathrm{SnO}_{2}$ : step 1, Formation of clear gel of precursors by stirring; step 2, forming nanopores in the $\mathrm{SnO}_{2}$ gel by boiling the alcohol and crystallizing the $\mathrm{SnO}_{2}$ pore walls by calcination

utilized to generate nanopores in the $\mathrm{SnO}_{2}$ monolith. Polycrystalline hierarchical $\mathrm{SnO}_{2}$ with well proportioned composition is also obtained in the pore walls of $\mathrm{SnO}_{2}$. Based on the large surface area and integrated pore systems, it is expected that the hierarchical porous $\mathrm{SnO}_{2}$ will play an important role in various applications, such as gas sensors, separation, lithium ion batteries and other fields.

Acknowledgments This work was supported by the UDF grant from The University of Hong Kong.

\section{References}

1. Su COM, Li S, Dravid VP (2003) J Am Chem Soc 125:9930

2. Law M, Kind H, Messer B, Kim F, Yang P (2002) Angew Chem Int Ed 41:2404

3. Graetzel M (2001) Nature 414:338

4. Zhang YL, Liu Y, Liu ML (2006) Chem Mater 18:4643

5. Harrison PG, Willet MJ (1988) Nature 332:337

6. Ferrere S, Zaban A, Gregg BA (1997) J Phys Chem B 101:4490
7. Stampfl SR, Chen Y, Dumesis JA, Niu C, Hill CG (1987) J Catal 105:445

8. Zhang DF, Sun LD, Yin JL, Yan CH (2003) Adv Mater 15:1022

9. Sears WM, Gee MA (1988) Thin Solid Films 165:265

10. Leja E, Korecki J, Toll K (1979) Thin Solid Films 59:147

11. Ye CH, Fang XS, Wang YH, Xie T, Zhao AW, Zhang LD (2004) Chem Lett 33:54

12. Wang JX, Liu DF, Yan XQ, Yuan HJ, Ci LJ, Zhou ZP, Gao Y, Song L, Liu LF, Zhou WY, Wang G, Xie SS (2004) Solid State Commun 130:89

13. Liu YK, Zheng CL, Wang WZ, Yin CR, Wang GH (2001) Adv Mater 13:1883

14. Juttukonda V, Paddock RL, Raymond JE, Denomme D, Richardson AE, Slusher LE, Fahlman BD (2006) J Am Chem Soc 128:420

15. Cheng B, Russell JM, Shi W, Zhang L, Samulski ET (2004) J Am Chem Soc 126:5972

16. Vayssieres L, Graetzel M (2004) Angew Chem Int Ed 43:3666

17. Zhao L, Yosef M, Steinhart M, Goring P, Hofmeister H, Gosele U, Schlecht S (2005) Angew Chem Int Ed 45:311

18. Dai ZR, Pan ZW, Wang ZL (2002) J Am Chem Soc 124:8673

19. Liu Y, Dong J, Liu M (2004) Adv Mater 16:353

20. Yang HG, Zeng HC (2004) Angew Chem Int Ed 43:5930

21. Lou XW, Wang Y, Yuan C, Lee JY, Archer LA (2006) Adv Mater 18:2325

22. Ishizuka N, Minakuchi H, Nakanishi K, Soga N, Tanaka N (1998) J Chromatogr A 797:133

23. Akin FA, Zreiqat $\mathrm{H}$, Jordan S, Wijesundara MBJ, Hanley L (2001) J Biomed Mater Res 64A:105

24. Wang XC, Yu JC, Ho C, Hou Y, Fu X (2005) Langmuir 21:2552

25. Chai GS, Shin IS, Yu JS (2004) Adv Mater 16:2057

26. Palomares E, Vilar R, Durrant JR (2004) Chem Commun 362

27. Blin JL, Leonard A, Yuan ZY, Gigot L, Vantomme A, Cheetham AK, Su BL (2003) Angew Chem Int Ed 42:2872

28. Coakley KM, McGehee MD (2003) Appl Phys Lett 83:3380

29. Fujishima A, Hashimoto K, Russian Watanabe T (1999) J Electrochem 35:1137

30. Li LL, Zhang WM, Yuan Q, Li ZX, Fang CJ, Sun LD, Wan LJ, Yan CH (2008) Cryst Growth Des 8:4165

31. Liang C, Shimizu Y, Sasaki T, Koshizaki N (2003) J Phys Chem B 107:9220

32. Moon T, Hwang ST, Jung DR, Son D, Kim C, Kim J, Kang M, Park B (2007) J Phys Chem C 111:4164

33. Ho WK, Yu JC, Lee SC (2006) Chem Commun 10:1115

34. Putnam RL, Nakagawa N, McGrath KM, Yao N, Aksay IA, Gruner SM, Navrotsky A (1997) Chem Mater 9:2690 